\title{
Perioperative Nursing Effect of Radiofrequency Thermocoagulation in the Treatment of Lumbar Disc Herniation
}

\author{
MING HUI. RUAN, LI QIANG. YANG, GUO QING. CAO, XIAO PING. WANG*AND JIA XIANG. NI \\ Department of Pain Management, Xuanwu Hospital of Capital Medical University, No.45 Changchun Street, Xicheng Zone, \\ Beijing 100053, China
}

Ruan et al.: Effect of radiofrequency thermocoagulation in the treatment of lumbar disc herniation To explore the effect of nursing intervention on the treatment of lumbar disc herniation with radiofrequency
thermocoagulation. The clinical data of 87 patients diagnosed with lumbar disc herniation treated at our
hospital from February 2018 to September 2019 were collected and divided into the control group (n=43)
and the observation group (n=44) according to the randomized double-blind method. The control group
was treated with routine nursing intervention, and the observation group was treated with comprehensive
nursing, the changes of lumbar vertebra function, complications, and quality of life after 1 and 3 mo of
intervention treatment were observed. At the same time, the pain degree of the two groups was evaluated
7 d after the operation. The results showed that the Oswestry disability index of the two groups decreased
significantly 1 mo and 3 mo after the operation (p<0.05), the score and the incidence of complications in the
observation group was significantly lower than that in the control group. On the 7 th d after the operation,
the visual analog scale score of the observation group was significantly lower than that of the control
group, and the difference between the two groups was statistically significant (p<0.05). After intervention
treatment, the scores of quality of life in the control group and the observation group were significantly
improved, and the quality of life in the observation group was significantly better than that in the control
group (p<0.05). The establishment of a correct and effective rehabilitation intervention program after
the operation cannot only significantly reduce the degree of pain and the risk of complications, but also
significantly improve the quality of life of patients, which is worth popularizing and applying in the clinic.

Key words: Lumbar disc herniation, radiofrequency thermocoagulation, comprehensive nursing, pain degree, quality of life

Lumbar pain (LBP) has become one of the most serious public health problems in the world. Its lifetime prevalence rate was as high as $84 \%$, and about $11 \%$ $-12 \%$ of patients were disabled due to $\mathrm{LBP}^{[1]}$. The prevalence rate of lumbar disc herniation in Chinese civil servants was the highest $(44.8 \%)^{[2]}$. However, the pathological mechanism leading to lumbar disc herniation was not clear. With the development of the economy, great changes have taken place in China's living, environmental, and working conditions. Lumbar disc herniation was one of the most common spinal degenerative diseases that lead to LBP and radiculopathy ${ }^{[3-6]}$. At present, surgical treatment was mainly used for lumbar disc herniation due to the advantages of fast curative effect and strong radical cure. However, it may also bring more pain to patients because of surgical trauma ${ }^{[7]}$. In recent $y$, with the rapid development of spinal surgery technology and continuous innovation in the treatment of lumbar disc herniation, minimally invasive technology has gradually replaced the traditional treatment, providing a safe and reliable treatment for patients who were ineffective in conservative treatment ${ }^{[8]}$. Radiofrequency thermocoagulation was a very effective treatment in minimally invasive therapy, which was widely used in the clinic, with the characters of no pain, no sequela, and small wounds ${ }^{[9-11]}$. At present, radiofrequency thermocoagulation was widely used in the treatment of a variety of acute and chronic pain diseases. This study aims to explore the effect of comprehensive nursing on radiofrequency thermocoagulation in the treatment of lumbar disc herniation. The clinical data of 87 patients with lumbar disc herniation treated in our hospital from February 2018 to September 2019 were collected and randomly divided into the control group $(n=43)$ and the observation group $(n=44)$. The control group was 
treated with routine nursing intervention and the observation group was treated with comprehensive nursing. Inclusion criteria: The age of the patient is 20-90 y old. The root pain of the patients lasted for more than 6-8 $\mathrm{w}$. The patient's intervertebral disc herniation was confirmed by Magnetic resonance imaging (MRI) as single-stage herniation and adjacent double-segmental hernia. The dry disc with the root of the body, the outer canalis spinalis was narrow; the unilateral protrusion was more than $1 / 3$ of the diameter of the spinal canal, accompanied by the stenosis of the lateral recess. Exclusion criteria: The intervertebral disc herniation below grade 2. Syndrome of cauda equina. Spontaneous spondylolisthesis or degenerative spondylolisthesis of intervertebral disc. Spinal canal stenosis. Patients during pregnancy or lactation. Suffering from a serious underlying illness or mental illness. After comparative analysis, the population distribution, clinical index, and surgical indication of the two groups were similar, and there was no statistical difference (Table 1, $\mathrm{p}>0.05$ ). The patients in the control group were given routine nursing care. The content of nursing includes the health education, explaining the occurrence mechanism and inducing factors of the disease to the patients and their families, and guiding the patients' postoperative pain intervention and functional exercise. The patients in the observation group given comprehensive nursing on the basis of routine nursing. The contents of comprehensive nursing were shown in Table 2. Through the establishment of a professional nursing team, a perfect nursing plan was made according to the patient's condition, psychological characteristics, and related learning situation. Comprehensive nursing mainly consists of five parts (team management, assessment management, pain management, health care management, and emotional management). Oswestry disability index ${ }^{[12]}$ was used to evaluate the lumbar vertebra function of the two groups before operation, 1 mo and 3 mo after the operation. The total score was 45; the higher score means the more serious of lumbar vertebra dysfunction. Visual analog scale (VAS) ${ }^{[13]}$ was used to evaluate the degree of lumbar vertebra pain in the two groups before operation and $7 \mathrm{~d}$ after the operation. The total score was 10 points. The higher the score, the more pain. Quality of life score. European Organization for Research and Treatment of Cancer Quality of Life Questionnare-Core 30 (EORTCQLQ-30) was used to evaluate the quality of life of the patients. The evaluation content mainly includes the patient's family support, psychological

TABLE 1: THE CLINICAL DATA OF THE PATIENTS

\begin{tabular}{lccc}
\hline \multicolumn{1}{c}{ Parameter } & Observation group $(\mathbf{n}=44)$ & Control group $(\mathbf{n}=43)$ & $\mathrm{p}$ value \\
\hline Age & $57.54 \pm 17.63$ & $58.26 \pm 11.24$ & 0.345 \\
Gender ratio (male/female) & $21: 23$ & $19: 24$ & 0.453 \\
Baric index $\left(\mathrm{kg} / \mathrm{c}^{\mathrm{m} 2}\right)$ & $18.37 \pm 1.58$ & $17.88 \pm 1.13$ & 0.864 \\
Operation time (hours) & $0.94 \pm 0.35$ & $0.92 \pm 0.40$ & 0.643 \\
Postoperative hospitalization (d) & $13.8 \pm 6.2$ & $13.6 \pm 7.8$ & 0.705 \\
Post-operative movement time (d) & $3.2 \pm 0.4$ & $2.8 \pm 0.2$ & 0.627 \\
Recovery of daily life (d) & $6.43 \pm 2.1$ & $6.51 \pm 2.0$ & 0.786 \\
Course of disease & $3.80 \pm 1.05$ & $3.90 \pm 1.10$ & 0.877 \\
\hline
\end{tabular}

\section{TABLE 2: THE COMPOSITION AND CONTENT OF COMPREHENSIVE NURSING}

\begin{tabular}{ll}
\hline Topic & Contents \\
\hline Team & A professional nursing team was set up, composed of 1 attending physician, 2 spinal nursing nurses, and 4 \\
management & $\begin{array}{l}\text { expert nurses. The members of the group mastered the nursing related knowledge of lumbar disc herniation } \\
\text { through study and training. }\end{array}$ \\
Assessment & Return visits were carried out twice a $w$ to obtain the patient's condition, psychology, and learning-related \\
management information. Discuss, develop, and adjust solutions within the group based on feedback. \\
Pain \\
According to the patient's personality characteristics and pain cognition and tolerance, reasonable arrangement \\
management of personalized nursing measures to relieve the postoperative pain, such as psychological cues, music therapy, \\
and physical and mental relaxation intervention. \\
Health care management can be divided into the basic rehabilitation intervention and stepwise rehabilitation \\
nursing intervention. In the basic rehabilitation intervention, auricular point pressing with beans was mainly \\
used to press the auricular points such as waist, kidney, liver, shenmen. Stepwise rehabilitation nursing \\
Health care \\
management intervention (physical function rehabilitation training) was carried out under the guidance of the doctor in \\
charge, including ankle pump exercise, isometric contraction exercise of musculi quadriceps femoris and \\
standing and walking training. \\
Actively listen to the demands of patients and dredge their emotions with mindfulness, the main measures \\
Emotional \\
management were communication, social support, music therapy.
\end{tabular}
management were communication, social support, music therapy. 
activities, daily life, health feelings, and activity ability. Using 1-4 grades for evaluation, the higher the grade, the higher the quality of life of the patients ${ }^{[14]}$. Comparative analysis of the adverse reactions between the two groups. The data were analyzed by SPSS 20.0 . The measurement data were expressed by $\overline{\mathrm{x}} \pm \mathrm{s}$ and analyzed by t-test. The counting data were expressed as $\%$ and analyzed by $\chi^{2}$ test. $\mathrm{p}<0.05$ indicates that the difference was statistically significant. As shown in Table 3. There was no significant difference in the lumbar function between the two groups $(\mathrm{p}>0.05)$. Compared with those before operation, the Oswestry disability index of the two groups decreased significantly 1 mo and 3 mo after the operation $(\mathrm{p}<0.05)$, and the score of the observation group decreased significantly, and there was significant difference between the two groups $(p<0.05)$. There was no significant difference in the preoperative lumbar pain score between the two groups ( $\mathrm{p}>0.05)$. On the 7 th $\mathrm{d}$ after the operation, the VAS score of the observation group was significantly lower than that of the control group, and the difference between the two groups was statistically significant (Table 4). The results showed that the quality of life scores in the two groups were significantly improved. Compared with the control group, the quality of life of patients in the observation group was significantly improved, and the difference between the two groups was statistically significant ( $<<0.05$, fig. 1 ). The results showed that after 3 mo of nursing, the incidence of postoperative complications in the observation group decreased significantly, and the difference was statistically significant $(p<0.05$, Table 5). Lumbar disc herniation always occurs in the nucleus pulposus and annulus fibrosus of the intervertebral disc. Lumbar disc herniation compression of nerve root was the main cause of low back pain. Radiofrequency thermocoagulation was a reliable method for the treatment of nerve root compression and intervertebral disc herniation, which has the advantages of less trauma to paraspinal muscles, less intraspinal fibrosis and lower recurrence rate ${ }^{[9-11]}$. However, the surgery cannot repair the damage of muscle and nerve function and structure caused by the surgical approach, which will cause local nerve or muscle dysfunction ${ }^{[15]}$. Therefore, nursing intervention and reasonable exercise guidance for the perioperative patients with lumbar disc herniation can accelerate the recovery of postoperative prognosis and improve the quality of life of patients. In this study, the comprehensive nursing scheme of lumbar disc herniation was established according to the

TABLE 3: EVALUATE THE LUMBAR FUNCTION OF THE TWO GROUPS BEFORE OPERATION, 1 MO AND 3 MO AFTER THE OPERATION

\begin{tabular}{lcccc}
\hline Oswestry disability index & Observation group & Control group & $\mathrm{x}^{2}$ & $\mathrm{p}$ value \\
\hline Before operation & $32.33 \pm 3.26$ & $31.87 \pm 3.13$ & 0.976 & 0.783 \\
1 mo after the operation & $21.26 \pm 1.28$ & $26.40 \pm 1.17$ & 6.217 & 0.001 \\
3 mo after the operation & $12.50 \pm 1.10$ & $17.45 \pm 1.25$ & 10.371 & 0.001 \\
\hline
\end{tabular}

TABLE 4: VAS PAIN SCORE OF PATIENTS IN TWO GROUPS

\begin{tabular}{|c|c|c|c|c|}
\hline VAS score & Observation group & Control group & $x^{2}$ & $p$ value \\
\hline Before operation & $7.73 \pm 0.78$ & $7.93 \pm 0.85$ & 1.251 & 0.687 \\
\hline $1 \mathrm{~d}$ after the operation & $3.53 \pm 0.34$ & $4.35 \pm 0.55$ & 2.355 & 0.041 \\
\hline $7 \mathrm{~d}$ after the operation & $2.14 \pm 0.23$ & $3.65 \pm 0.21$ & 4.743 & 0.025 \\
\hline
\end{tabular}

Before operation

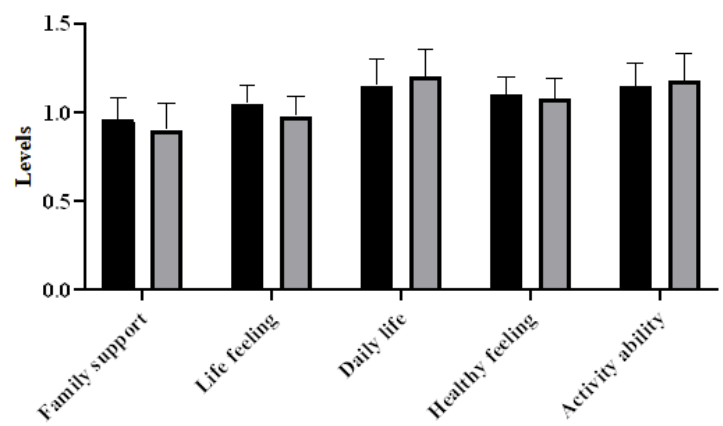

After operation

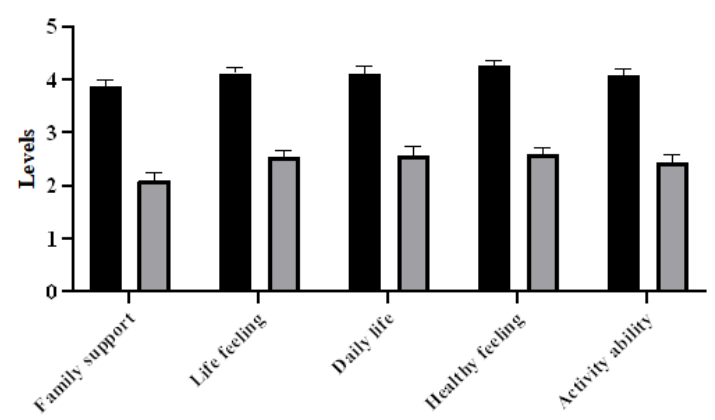

Fig. 1: Quality of life scores of patients in two groups 
TABLE 5: ADVERSE REACTIONS IN THE TWO GROUPS

\begin{tabular}{|c|c|c|c|c|}
\hline VAS score & Observation group & Control group & $x^{2}$ & $p$ value \\
\hline Infection of incisional wound & $4(9.30 \%)$ & $2(4.55 \%)$ & & \\
\hline Intervertebral space infection & $2(4.65 \%)$ & $1(2.28 \%)$ & & \\
\hline Epidural hematoma & $1(2.33 \%)$ & $1(2.28 \%)$ & & \\
\hline Leakage of cerebrospinal & $1(2.33 \%)$ & $0(0.00)$ & & \\
\hline Deep venous thrombosis & $0(0.00)$ & $1(2.28 \%)$ & & \\
\hline Nerve damage & $1(2.33 \%)$ & $0(0.00)$ & & \\
\hline Incidence of complications & $9(20.63 \%)$ & $5(11.38 \%)$ & 4.217 & 0.021 \\
\hline
\end{tabular}

principle of evidence-based medicine, which aims to improve the prognosis and quality of life of patients after the operation. In this study, a professional nursing team was set up, and the intervention program was divided into five parts, team management, evaluation management, pain management, health care management, and emotional management. In the process of comprehensive nursing, we pay attention to the real-time feedback of patients and grasp the changes of patients' condition, mood, and pain. By formulating and modifying a personalized plan, we can help patients reduce the perioperative pain, eliminate pain sensitivity caused by the negative emotions, and improve the patients' pain tolerance. At the same time, the traditional Chinese medicine characteristic physical technology auricular point pressing with beans was used for basic rehabilitation training, to improve the immune function of patients and promote the metabolism of the body, thus to accelerate the recovery of prognosis and reduce the risk of postoperative complications. In addition, the doctor in charge personally instructs the patients to carry out some physical function training, to make the patients adapt to the rhythm of postoperative rehabilitation and enhance their confidence in overcoming the disease. At the same time, through communication and counseling, social support, music therapy, and other methods to reduce patients' negative emotions. The results showed that the lumbar function, VAS pain score, and incidence of postoperative complications in the observation group were significantly lower than those in the control group at 1 and 3 mo after the operation, and the difference was statistically significant $(p<0.05)$, which was consistent with the results of other studies ${ }^{[16-18]}$. In addition, we also found that after treatment, the quality of life of patients in the observation group was significantly improved, indicating that our comprehensive nursing regimen can reduce the degree of postoperative pain significantly and improve the quality of life of patients with lumbar disc herniation. To sum up, the establishment of a correct and effective rehabilitation intervention program after the operation can not only significantly reduce the degree of pain and the risk of postoperative complications, but also significantly improve the quality of life of patients after the operation, which is worth popularizing and applying in the clinic.

\section{Acknowledgement:}

This work was supported by Xuanwu Hospital of Capital Medical University.

\section{Declaration of interest:}

The authors report no conflicts of interest.

\section{REFERENCES}

1. Bydon M, Moinuddin F M, Yolcu Y U, Wahood W, Alvi MA, Goyal A, et al. Lumbar intervertebral disc mRNA sequencing identifies the regulatory pathway in patients with disc herniation and spondylolisthesis. Gene 2020:144634.

2. Guo S, Lu D, Pfeiffer S, Pfeiffer DU. Non-ambulatory dogs with cervical intervertebral disc herniation: single versus multiple ventral slot decompression. Aust Vet J 2020;98:14855.

3. Du CF, Liu CJ, Huang YP, Wang X. Effect of Spiral Nucleus Implant Parameters on the Compressive Biomechanics of Lumbar Intervertebral Disc. World Neurosurg 2020;134:e87884.

4. Cosamalón-Gan I, Cosamalón-Gan T, Mattos-Piaggio G, Villar-Suárez V, García-Cosamalón J, Vega-Álvarez JA. Inflammation in the intervertebral disc herniation. Neurocirugía 2020.

5. Wang W, Ni BB, Shen H, Lu H. Comparison of surgical outcomes of lumbar disc herniation using local anesthesia and epidural anesthesia: A meta-analysis. Medicine 2020;99.

6. Chen X, Chamoli U, Vargas Castillo J, Ramakrishna VA, Diwan AD. Complication rates of different discectomy techniques for symptomatic lumbar disc herniation: a systematic review and meta-analysis. Eur Spine J 2020:1-9.

7. Shibata T, Iimuro Y, Yamamoto Y, Maetani Y, Ametani F, Itoh $\mathrm{K}$, et al. Small hepatocellular carcinoma: comparison of radiofrequency ablation and percutaneous microwave coagulation therapy. Radiology 2002;223:331-7.

8. Ahmed M, Liu Z, Lukyanov AN, Signoretti S, Horkan C, Monsky WL, et al. Combination radiofrequency ablation with intratumoral liposomal doxorubicin: effect on drug accumulation and coagulation in multiple tissues and tumor types in animals. Radiology 2005;235:469-77.

9. Samaha EI, Ghanem IB, Moussa RF, Kharrat KE, Okais 
NM, Dagher FM. Percutaneous radiofrequency coagulation of osteoid osteoma of the "Neural Spinal Ring". Eur Spine J 2005; 14:702-5.

10. Moles A, Guénot M, Rheims S, Berthiller J, Catenoix H, Montavont A, et al. SEEG-guided radiofrequency coagulation (SEEG-guided RF-TC) versus anterior temporal lobectomy (ATL) in temporal lobe epilepsy. J Neurol 2018;265:19982004.

11. Konnerth CG, Seitz D, Folz BJ. Radiofrequency Surgery (RF Coagulation) for Treatment of recurrent Epistaxis. GMS 2008.

12. Ling-Ling W. Nursing care of patients with lumbar disc herniation treated by ozone ablation combined with radiofrequency thermocoagulation. J Clin Med Lit 2018.

13. Lurie JD, Berven SH, Gibson-Chambers J, Tosteson $\mathrm{T}$, Tosteson A, Hu SS, et al. Patient preferences and expectations for care: determinants in patients with lumbar intervertebral disc herniation. Spine 2008;33:2663.

14. Qihua W, Jing YU, Jilan Y. The Effect of Comprehensive Nursing Intervention on Postoperative Rehabilitation in Patients with Lumbar Intervertebral Disc Herniation. Chin Cont Med Edu 2017.

15. Schaufele $\mathrm{M} \mathrm{K}$, Hatch L, Jones W. Interlaminar versus transforaminal epidural injections for the treatment of symptomatic lumbar intervertebral disc herniations. Pain Physician 2006;9:361-6.

16. Lurie JD, Tosteson TD, Tosteson AN, Zhao W, Morgan TS, Abdu WA, et al. Surgical versus nonoperative treatment for lumbar disc herniation: eight-year results for the Spine Patient Outcomes Research Trial. SPINE 2014;39:3-16.

17. Silverplats K, Lind B, Zoëga B, Halldin K, Gellerstedt M, Brisby $\mathrm{H}$, et al. Clinical factors of importance for outcome after lumbar disc herniation surgery: long-term follow-up. Eur Spine J 2010;19:1459-67.

18. Xiaoju C. Application of "one chain for one disease" nursing service in lumbar disc herniation surgery. Anhui Med Pharm J 2016.

This is an open access article distributed under the terms of the Creative Commons Attribution-NonCommercial-ShareAlike 3.0 License, which allows others to remix, tweak, and build upon the work non-commercially, as long as the author is credited and the new creations are licensed under the identical terms

This article was originally published in a special issue,
"Biomedical Research in Clinical and Preclinical
Pharmaceutics" Indian J Pharm Sci 2020:82(5)Spl
issue7;134-138

